\title{
Visual Outcome of Cataract Surgery
}

\section{CU Ukponmwan MBBS, FMCOphth, FWACS; EU Ogborogu, MBBS; W Ovienria, MBBS}

University of Benin Teaching Hospital, Benin City, Nigeria

\section{ABSTRACT \\ Purpose: To assess the visual outcome of cataract surgery in a tertiary hospital in Nigeria.}

Methods: Three hundred and seventy eyes (370) that had cataract surgery in the ophthalmology department of University of Benin Teaching Hospital (UBTH) from July 2007 to Decem ber 2008 w ere included in the study. Case records were retrieved and data from them analysed. The age range was 4 to 95 years (mean age 41.1 years). There were 181 males and 189 females .

Senile cataract was the commonest $(64.6 \%)$ type, followed by traumatic cataract (13\%). Extracapsular cataract extraction with posterior chamber intraocular lens (IOL) implant (75.4\%) was the commonest procedure, followed by ECCE with anterior chamber intraocular lens implant (11.6\%), ECCE without IOL $(4.1 \%)$ and intracapsular cataract extraction with or without IOL ( $8.9 \%$ ).

Results: Preoperative visual acuity was less than 3/60 in $73.8 \%$ and $6 / 18-6 / 60$ in $4 \%$ of the eyes. The best corrected postoperative visual acuity at $6 \mathrm{weeks}$ was $6 / 6-6 / 18$ (good outcome) in $161(43.5 \%)$ eyes, borderline in $107(28.9 \%)$ and poor in $73(19.7 \%)$. The best corrected visual outcome at 6 months was good in $221(59.7 \%)$, borderline in $59(15.9 \%)$ and poor in 34 $(9.3 \%)$ eyes. The visual outcome was unknown in 56 $(15.1 \%)$ eyes

Conclusion: The visual outcome after cataract extraction in this centre is still less than the WHO recommendation of $90 \%$ for best corrected visual acuity of $6 / 6-6 / 18$ vision. There is the need for biometry, good patient selection, proper management of complications and spectacle correction of refractive errors in order to improve visual outcome after cataract extraction.

Key words: visual outcome, cataract extraction, intraocular lens implant

\section{INTRODUCTION}

Vision loss from cataract represents an estimated 50\% or more of the global burden of blind ness. ${ }^{1}$ Cataract is the most important cause of reversible blindness in people above 40 years of age in Nigeria. ${ }^{2}$ It is also known to be the commonest cause of severe visual impairment in this age group. ${ }^{2}$ The National Blindness and Visual Impairment Survey conducted in Nigeria between 2005 and 2007 reported the prevalence of cataract blindness to be $1.8 \%{ }^{2}$ Cataract was the commonest cause of severe visual impairment and blindness in people aged 40 years and above being responsible for $45.3 \%$ and $43 \%$ respectively. ${ }^{2}$

The development of cataract is not only genetically determined but also has to do with nutritional status and environmental influences. ${ }^{3}$ More blind people exist in developing countries; the majority of them live in the poor rural communities where hospitals and surgical facilities are in great deficit. ${ }^{2-4}$ Blindness from cataract increases as the eld erly population increases due to increased longevity. ${ }^{5}$ The objective of performing cataract surgery is not only to restore visual function at the organ level but also to restore visual functioning and ind ependence to the person. ${ }^{1}$ Several studies have reported an association between improved visual function after surgery and improved health related quality of life. ${ }^{6,7}$

To effectively reduce the cataract back log in Edo State, free cataract outreach programmes have become necessary. The Department of Ophthalmology at the University of Benin Teaching Hospital entered into a partnership with a non-governmental organization (Amen Foundation) to commence a free cataract surgery programme in January 2008. Since its inception, the patient turnout for cataract surgery has increased.

The World Health Organization (WHO) categorizes the outcome of cataract surgeries into 3 groups: good (visual acuity of 6/ 6-6/ 18), bord erline (visual acu ity of $<6 / 18-6 / 60$ ) and poor (visual acuity $<6 / 60$ ). It has also recommended and set targets aimed at achieving good uncorrected visual acuity in at least $80 \%$ of surgeries and poor in less than $5 \%$, and corrected visual acu ity of good in $90 \%$ of surgeries and poor in less than $5 \%$ by 2 months after surgery. ${ }^{8}$

This study was designed to find out the visual outcome of patients who had cataract surgery at the University of Benin Teaching Hospital between July 2007 and December 2008 and to assess the success of the free cataract surgery programme. This will also encourage eye surgeons to monitor their own results over time and improve on the visual outcome.

*Correspondence: Dr Catherine. U. Ukponmwan, Dept of Ophthalmology, School of Medicine, University of Benin, PMB 1111, Benin City, Nigeria・e-mail:kateukponmwan@yahoo.com 


\section{MATERIALS AND METHODS}

All consecutive patients who had cataract surgery in the ophthalmology department of the University of Benin Teaching Hospital (UBTH) from July 2007 to Decem ber 2008 were included in this study. Patients excluded from the study were those below 4 years of age due to poorly assessed visual acuities, patients who had combined trabeculectomy and cataract extraction with IOL, eyes with no perception of light preoperatively and patients with incomplete records.

The patients were followed-up for 6 months postoperatively. All patients' files were retrieved, data was recorded and analysed. Three hundred and seventy eyes (370) of 358 patients were included in the study. Demographic data such as age, sex, occupation, tribe, associated systemic/ocular conditions, preoperative and postoperative visual acuity, systemic and ocular examination findings, type of surgery done and the type of intraocular lens inserted were noted.

The patients were admitted and prepared one day before surgery. General physical and ocular examinations were performed. The patients were given tablets of diazepam $5 \mathrm{mg}$ and acetazolamide $250 \mathrm{mg}$ the night before surgery. Chloram phenicol eye drops w ere instilled in to both eyes. The patients were given $500 \mathrm{mg}$ of acetazolamide tablet on the morning of the operating day. The pupil was dilated $w$ ith trop icam id e or cyclopentolate. Local an aesthesia (facial and retrobulbar), using $2 \%$ lignocaine or xylocaine with or without adrenaline and $0.5 \%$ bupivacaine, was used for adults while general anaesthesia was used for children. All operations were perform ed with operating microscopes. No biometry was done because the equipment was not available. The intraocular lens power was calculated from the previous refraction of the patient in the affected eye if available or the other eye, or the lens was selected from a standard stock available in the hospital.

Stand ard extra capsular cataract extraction (ECCE) with posterior or anterior chamber IOL (PCIOL/ ACIOL) was mostly done. A fornix based conjunctival flap was used. A limbal incision was made superiorly. Viscoelastic material was used to maintain the anterior chamber depth and ringer's lactate w as u sed as irrigating fluid. The IOL in serted was a single piece intraocular lens and the power was between $+18.5 \mathrm{D}$ and $+22.5 \mathrm{D}$. Anterior chamber IOL (AC IOL) was inserted in patients with preoperative subluxated or dislocated cataract or intraoperative rupture of the posterior capsule. Subconjunctival injection of ceftazidime $100 \mathrm{mg}$, gentamicin $20 \mathrm{mg}$ and dexamethasone $4 \mathrm{mg}$ was given at the end of the operation, ciprofloxacin or chloramphenicol, tropicamide and dexamethasone or bethamethasone eyedrops were instilled at the end of surgery. Postoperative medication included topical antibiotics/steroid/mydriatic (ciprofloxacin, chloramphenicol, bethamethasone, tropicamide), oral acetazolamide/ analgesic/ascorbic acid. Patients without complications after surgery were discharged the next day.
The majority of the patients, $273(73.8 \%)$ were blind with visual acuity $<3 / 60,15(4.2 \%)$ had visual acuity of 6/ 18 to $6 / 60$ and $82(22.2 \%)$ had visual acuity less than $6 / 60$ to $3 / 60$. There was no patient with visual acuity better than 6/ 18.

The types of cataract were senile cataract in $239(64.6 \%)$ eyes, traumatic/ dislocated cataract in $48(13 \%)$ eyes, post uveitic (complicated) in $37(10 \%)$ eyes, congenital/ developmental in 27 (7.3\%) eyes, and diabetic cataract in 19 (5.1\%) eyes.

Extracapsular cataract extraction (ECCE) with posterior chamber IOL w as perform ed in 279 (75.4\%) eyes, ECCE w ith AC IOL w as performed in 43 (11.6) eyes, ECCE without IOL in $15(4.1 \%)$ eyes, ICCE (intracapsular cataract extraction) with AC IOL in $14(3.8 \%)$ eyes, ICCE without IOL in 19 $(5.1 \%)$ eyes. Intracap su lar cataract extraction w as performed in patients with subluxated or dislocated cataract.

Postoperative visual acuity was assessed using the Snellen's chart with or without pinhole $(\mathrm{PH})$ on $1^{\text {st }} \mathrm{d}$ ay post operative ( $1^{\text {st }}$ DPO), 1 week, 6 weeks, 3 months and 6 months. Postoperative refraction was done at $6 \mathrm{w}$ eeks. The visual acuity was classified according to the World Health Organization recommendation of good being 6/6-6/ 18, borderline (fair) $<6 / 18-6 / 60$ and poor $<6 / 60$. $^{8}$

The data was then analysed using EPI info 13 . Frequencies, mean and chi square were calculated. P value $\leq 0.05 \mathrm{w}$ as taken as significant.

\section{RESULTS}

The total number of patients operated on during the period was 412 . The patients included in the study were 358 and the total number of eyes was 370 . There were 346 unilateral cases and 12 bilateral cases. Forty patients were lost to follow up at the end of 6 months. Children less than 4 years were excluded from the study.

There were 181 males and 189 females and the male to female ratio $w$ as approximately $1: 1$. The age range was 4 to 95 years with a mean of 41.1 years. The age distribution of the patients is shown in table 1. The highest number of patients was recorded in age group 61-70 years. The majority of the patients $(67.1 \%)$ were above 50 years. Forty (40) patients ( 27 males and 13 females) were lost to follow up.

Table 2 shows the best corrected visual acuity of the patients on the $1^{\text {st }}$ postoperative day, and at $1 \mathrm{w}$ eek, $6 \mathrm{w}$ eeks, 12 weeks and 24 weeks ( 6 months) post op. The visual acu ity was 6/ 6-6/ 18 in $30(8.1 \%)$ eyes on the $1^{\text {st }} \mathrm{day}$ post op and this increased to $221(59.7 \%)$ eyes at the end of 6 months. Visual acuity $<6 / 18-6 / 60 \mathrm{w}$ as recorded in $67(18.2 \%)$ eyes on the $1^{\text {st }}$ day post op and this reduced to $59(15.9 \%)$ eyes at 6 months. On the first day post op, visual acuity $<6 / 60$ was present in $273(73.8 \%)$ eyes and it reduced to $34(9.2 \%)$ at 6 months. The best corrected VA of 6/6-6/ 18 was present in $161(43.5 \%)$ eyes at 6 weeks, $202(54.6 \%)$ eyes at 3 months and $221(59.7 \%)$ eyes at 6 months. Visual acuity less than 
3/ 60 to light perception was present in 79 eyes on the $1^{\text {st }}$ day post op and this number reduced to 13 at 6 months. Nineteen (19) eyes were lost to follow up at $6 \mathrm{w}$ eeks and this increased to 40 at 6 months. The total number of eyes at 6 months was 330 .

Table 1. Age distribution of the patients

\begin{tabular}{lcc}
\hline Age Range & No of Eyes & Percentage \\
\hline $1-10$ & 39 & 10.5 \\
$11-20$ & 15 & 4.1 \\
$21-30$ & 12 & 3.2 \\
$31-40$ & 21 & 5.6 \\
$40-50$ & 35 & 9.5 \\
$51-60$ & 82 & 22.2 \\
$61-70$ & 111 & 30.0 \\
$71-80$ & 37 & 10.0 \\
$>80$ & 18 & 4.9 \\
\hline Total & 370 & 100 \\
\hline
\end{tabular}

Table 3 shows the visual outcome at 6 months in patients aged less than 50 years of age and greater than 50 years of age, and according to sex. There was no statistically significant difference in terms of visual outcome between those aged less than 50 years and patients above 50 years of age $(\mathrm{P}=0.0801)$. There was no statistically significant difference in visual ou tcome between the males and females $(P=0.9789)$. The table also show s the type of cataract and the visual ou tcome at $6 \mathrm{~m}$ onths. Patients with senile cataract had the highest number of good visual outcome.

The pre-existing system ic diseases w ere hypertension in 93 patients, diabetes in 34 patients, card iovascular disease in
2 patients and HIV/ AID in 9 patients. Two hundred and forty-four patients did not have any systemic disease. Some of the patients had more than one systemic condition. The pre-existing ocular conditions were glaucoma in 47 eyes, uveitis in 28 eyes, age related maculopathy in 212 eyes, diabetic retinopathy in 15 eyes, hypertensive retinopathy in 13 eyes and retinal detachment in 1 eye. Some patients had multiple disease conditions. There was no pre-existing disease in 96 eyes. The visual outcome was good in 169 $(79.7 \%)$ of the eyes with age related maculopathy. Only 6 out of the 212 eyes had poor visual outcome. Fourteen (14) out of the 28 eyes with uveitis had poor visual outcome. There was a significant difference in visual outcome between eyes with uveitis and those without uveitis $(\mathrm{p}<0.0001)$. The visual outcome was good in 9 eyes with glaucoma, fair in 32 eyes and poor in 4 eyes. There was a significant difference in the visual outcome between eyes with glaucoma and those without $(\mathrm{p}<0.0001)$ Two patients did not come for follow up.

The com monest in traoperative com plication seen in th is study was posterior capsular rent in 31 eyes $(8.4 \%)$. It was associated with vitreous loss in 25 eyes and without vitreous loss in 6 eyes. The other intraoperative complications were stripping of descemets membrane in 18 eyes $(4.8 \%)$, hyphaema in 8 eyes $(2.2 \%)$, zonular dehiscence and retinal detachment in 1 eye each. The early and late postoperative complications are shown in table 4 . Tw o hundred and thirty nine eyes (239) developed early postoperative complications ranging from striate keratopathy in 158 eyes $(42.7 \%)$ to endophthalmitis in 2 eyes $(0.6 \%)$. The visual outcome was fair in the two eyes with endophthalmitis. There was early resolution of striate keratopathy without any effect on the visual outcome in all the patients. The commonest late post operative complication was cystoid macular oedema in 9 eyes $(2.4 \%)$. The visual outcome was fair in 6 of the 9 eyes and poor in 3 eyes. Five (5) out of the 6 eyes with posterior capsular opacification had poor vision.

Table 2. Visual acuity on $1^{\text {st }}$ post-operative day, 1 week, 6 w eeks, 12 weeks ( 3 months), 24 w eeks ( 6 months)

\begin{tabular}{lcccccccccc}
\hline VA & $1^{\text {st }}$ DPO & $\%$ & $1 \mathrm{wk}$ & $\%$ & $6 \mathrm{wks}$ & $\%$ & $3 \mathrm{mths}$ & $\%$ & $6 \mathrm{mths}$ & $\%$ \\
\hline $6 / 6-6 / 18$ & 30 & 8.1 & 79 & 21.4 & 161 & 43.5 & 202 & 54.6 & 221 & 59.7 \\
$<6 / 18-6 / 60$ & 67 & 18.2 & 131 & 35.4 & 107 & 28.9 & 75 & 20.2 & 59 & 15.9 \\
$<6 / 60-3 / 60$ & 194 & 52.4 & 128 & 34.6 & 55 & 14.9 & 32 & 8.6 & 21 & 5.7 \\
$<3 / 60-\mathrm{HM}$ & 48 & 12.9 & 17 & 4.6 & 7 & 1.9 & 6 & 1.7 & 5 & 1.4 \\
LP & 31 & 8.37 & 15 & 4.05 & 11 & 2.97 & 7 & 1.89 & 8 & $2 . .16$ \\
VA not recorded & 0 & 0 & 0 & 0 & 10 & 2.7 & 19 & 5.1 & 16 & 4.3 \\
Lost to follow -up & 0 & 0 & 0 & 0 & 19 & 5.2 & 29 & 7.8 & 40 & 10.8 \\
\hline TOTAL & 370 & 100 & 370 & 100 & 370 & 100 & 370 & 100 & 370 & 100 \\
\hline
\end{tabular}


Table 3. Visual outcome at 6 months in relation to age, sex and type of cataract

\begin{tabular}{|c|c|c|c|c|c|c|c|c|c|}
\hline Visual Outcome & Good & $\%$ & Fair & $\%$ & Poor & $\%$ & $\begin{array}{l}\text { Lost to } \\
\text { Follow Up }\end{array}$ & $\%$ & Total \\
\hline \multicolumn{10}{|l|}{ Age } \\
\hline Less than 50 years & 78 & 63.9 & 22 & 18.1 & 15 & 12.1 & 7 & 5.7 & 122 \\
\hline$>50$ years & 113 & 45.6 & 66 & 26.6 & 36 & 14.5 & 33 & 13.3 & 248 \\
\hline \multicolumn{10}{|l|}{$\operatorname{Sex}$} \\
\hline Male & 81 & 44.8 & 40 & 22.1 & 33 & 18.2 & 27 & 14.0 & 181 \\
\hline Female & 85 & 45.0 & 48 & 25.4 & 43 & 22.7 & 13 & 6.9 & 189 \\
\hline \multicolumn{10}{|l|}{ Type of Cataract } \\
\hline Senile & 121 & 50.6 & 65 & 27.2 & 45 & 18.8 & 8 & 3.34 & 239 \\
\hline Traumatic & 7 & 14.6 & 11 & 22.9 & 18 & 37.5 & 12 & 25.0 & 48 \\
\hline Dislocated Diabetic & 8 & 42.1 & 3 & 15.8 & 2 & 10.5 & 6 & 31.6 & 19 \\
\hline Post Uveitic & 5 & 13.5 & 6 & 16.2 & 16 & 43.2 & 10 & 27.1 & 37 \\
\hline Congenital & 5 & 18.5 & 17 & 63.0 & 1 & 3.7 & 4 & 14.8 & 27 \\
\hline
\end{tabular}

Table 4. Post-operative complications

\begin{tabular}{|c|c|c|}
\hline Complications & No of eyes & $\%$ \\
\hline \multicolumn{3}{|c|}{ Early post-operative complications } \\
\hline Striate keratip athy & 158 & 42.7 \\
\hline Cortical remnants & 33 & 8.8 \\
\hline Shallow anterior chamber & 12 & 3.2 \\
\hline Post-operative uveitis & 11 & 3.0 \\
\hline Conjunctival discharge & 9 & 2.4 \\
\hline Elevated IOP & 5 & 1.4 \\
\hline Endophthalmitis & 2 & 0.6 \\
\hline Pupillary capture & 2 & 0.6 \\
\hline Nil & 131 & 35.4 \\
\hline Total & 370 & 100.0 \\
\hline \multicolumn{3}{|c|}{ Late post-operative complications } \\
\hline Cystoid macular oedema & 9 & 2.4 \\
\hline Elevated IOP & 6 & 1.6 \\
\hline Posterior capsular rent & 6 & 1.6 \\
\hline Pupillary membrane & 3 & 0.8 \\
\hline Ocular hypotony & 2 & 0.5 \\
\hline Bullous keratopathy & 2 & 0.5 \\
\hline Phthisis bulbi & 1 & 0.3 \\
\hline Lost IOL & 1 & 0.3 \\
\hline Retinal detachment & 1 & 0.3 \\
\hline Nil & 299 & 80.8 \\
\hline Lost to follow up & 40 & 10.8 \\
\hline Total & 370 & 100.0 \\
\hline
\end{tabular}

\section{DISCUSSION}

More females than male patients had cataract surgery in this study although the ratio was $1: 1$ contrary to other reports from Nigeria which show a male preponderance in the uptake of cataract surgical services. ${ }^{11-13}$ This is likely to be due to the free cataract surgery programme which was introduced in the hospital thus making cataract surgery accessible and easily affordable to both male and female patients.

Patients above 50 years of age constituted $67.02 \%$ and the highest number was in the age group 61-70 years, sim ilar to other studies which also reported that senile cataract was the commonest type of cataract. ${ }^{12,13} \mathrm{Adio}^{12}$ reported that $66.6 \%$ w ere above 50 years. The least number of patients w as between 11 and 20 years and $40.1 \%$ of them presented mainly with complicated cataract.

Senile cataract was the commonest type of cataract affecting $64.6 \%$ of eyes in this study. ECCE/ PCIOL was highest because it is the usual type of surgery done. The other types of surgery are usually d one in complicated cases such as subluxated or dislocated cataract or for patients w ith intra operative complication s such as posterior capsular rent with vitreous loss. This result is similar to other studies. ${ }^{11-14}$

The majority of eyes, 273 (73.8\%), had a presenting visual acuity of $<3 / 60$ and this reflects the reluctance of patients in Nigeria to undergo cataract surgery unless they are blind. This is similar to reports from other studies. ${ }^{11-14}$ Adio ${ }^{12}$ reported that $93 \%$ of the eyes in their study had presenting visual acuity of $3 / 60$ or less while Nwosu ${ }^{11}$ reported $87.8 \%$. Patients should be encouraged to undergo cataract surgery earlier before becoming blind to reduce the unnecessary hardship and the economic burden to themselves, their families, and the society as a whole. They should be told of the availability of free cataract surgery and the public should be informed about the services rendered in ophthalmic hospitals or eye centres near them.

The visual acuity of the patients gradually improved in 30 eyes $(8.1 \%)$,w ith $6 / 6-6 / 18$ on the first post-operative day to 202 eyes $(54.6 \%)$ at 3 months post op to $221(59.7 \%)$ at 6 months post op. This improvement was as a result of the 
resolution of ocular inflammation from surgery and correction of any refractive error by the provision of adequate and proper spectacle correction. Various studies have shown similar improvement in visual acuity over time. ${ }^{11-15}$ It took an average of 2-3 months with a range of 2-5 months in the study by Nwosu ${ }^{11}$ for the patients to achieve optimal vision post-operatively. A pilot study carried out showed that optimal visual outcome was reached at 6 months or more after cataract surgery and that the WHO visual outcome targets are realistic. ${ }^{16} \mathrm{Chirambo},{ }^{16}$ in a pilot study, reported presenting good visual outcome in $66.5 \%$ and best corrected visual outcome in $80.2 \%$ between a 1 to 7 week post operative period, best borderline of $15.6 \%$ and poor best visual outcome of $4.3 \%$. The visual outcome improved to best corrected good visual outcome of $91.1 \%$, borderline of $4.2 \%$ and poor visual outcome in $4.7 \%$ at 26 weeks and above in the postoperative period.$^{16}$ Limburg et al. ${ }^{15}$ reported that $31 \%$ of eyes had good visual outcome at discharge and this improved to $69 \%$ at 8 weeks or more in the postoperative period while poor outcome was $17 \%$ at discharge, and decreased to $5 \%$ at $8 \mathrm{weeks}$ or more in the postoperative period. Adepoju ${ }^{17}$ reported good visual outcome of $83.3 \%$ at one year.

The reasons for the improvem ent of visual acuities after 6 weeks postoperatively were the resolution of intraocular inflammation resulting from surgery and the correction of residual refractive error. The visual outcome at 6 months revealed that $35.3 \%$ of patients with good visual outcome were less than 50 years of age while $51.3 \%$ were older than 50 years. There was no statistically significant difference between the two groups in terms of visual outcome. Ad io ${ }^{12}$ also reported that the visual outcome seemed better in patients older than 50 years of age. The visual outcome has been reported to be poorer in those less than 50 years of age and older than 80 years of age at the time of surgery. ${ }^{2}$

Patients with senile cataract had good visual outcome in $51.9 \%$, fair in $27.9 \%$ and poor in $16.5 \%$, while in eyes with traumatic cataract, the visual outcome was good in $14.6 \%$, fair in $22.9 \%$ and poor in $37.6 \%$. The highest numbers of patients with good visual outcome were those with senile cataract. This is because most of them are uncomplicated cataract. Other studies have also reported better visual outcome in patients with senile cataract compared to the visual outcome in other types of cataract. ${ }^{12}$

WHO recommended that for adequate visual outcome results, the postoperative visual acuity of good, 6/ 6-6/ 18 with available correction, should be greater than $80 \%$ and with best correction, it should be greater than $90 \%$, borderline (fair) outcome: <6/ 18-6/60 with available correction, it should be less than $15 \%$ and less than $5 \%$ with best correction. Poor outcome $<6 / 60$ with available correction should be less than $5 \%$ and with best correction $>5 \%{ }^{8}$

The good visual outcome of $59.7 \%$ at 6 months postoperatively in our study is less than the WHO recommendation but is similar to the outcome in other studies from Nigeria. ${ }^{11-13}$ Bekibele $^{13}$ reported good visual outcome with correction in $55.7 \%$ while $\mathrm{Nwosu}{ }^{11}$ reported that $58.9 \%$ had good visual outcome.

The main reasons for poor visual outcome following cataract surgery are poor case selection, surgical complications, uncorrected refractive error and post operative complications. ${ }^{18,19}$ The use of stand ard intraocular lens powers instead of calculating the powers by biometry also contributed to the poor visual ou tcome. The ou tcome in eyes with significant other pathology is likely to be poor. In this study, 14 out of the 28 eyes with complicated cataract from uveitis had poor visual outcome. The visual outcome was good in only $9(19.1 \%)$ out of the 47 eyes with glaucoma, fair in $32(68.1 \%)$ eyes and poor in 4 eyes. The visual outcome was good in 169 out of the 212 eyes with age-related macular degeneration, fair in 31 eyes and poor in 6 eyes. The presence of age related macular degeneration has been highlighted as an important risk factor for poor visual ou tcome after cataract extraction..$^{20}$ The improvement in visual acuity after cataract extraction in eyes with agerelated macular degeneration depends on the severity of the disease. ${ }^{21}$ Ferooghian et al., ${ }^{21}$ in their study on visual outcome in patients with $\mathrm{AMD}$, reported a statistically significant gain in visual acuity in patients with AMD and the degree of improvement varied with the severity of the disease. Patients with mild AMD gained more letters compared to those with advanced AMD. This demonstrates the effect that existing ocular diseases can have on the visual outcome after cataract surgery. A thorough ocular examination before surgery is very important to detect existing ocular diseases. It is important to in form the patient about the risk and probability of poor outcome following surgery. Complications at the time of surgery or postoperatively are also responsible for much of the visual impairment in operated eyes. The commonest late post operative complication in this study was cystoid macular oedema in $9(2.4 \%)$ eyes, and 6 of these eyes had fair vision. Posterior cap sular opacification occurred in 6 eyes (1.6\%), 5 of which had poor vision. The visual acuity can be improved in eyes with posterior capsular op acification by N eodynium yag laser capsulotomy or by non laser capsulotomy using a $25 \mathrm{G}$ capsulotomy need le. ${ }^{22}$

From the perspective of the patient, the reason behind the poor outcome is less important than the fact that poor vision exists. The patient may not be able to distinguish between vision deterioration associated with onset of new ocular pathologies versus that associated with surgical complications or undetected coexisting disease. Patients with poor vision may conclude that cataract surgery is only partially or tem porarily effective in restoring sight. We must do more to ensure that to the greatest extent possible, the result is complete sight restoration. The need to produce consistently good surgical outcomes is becoming important as patients in developing countries are increasingly seeking cataract surgery earlier before severe visual impairment.

Better outcomes of cataract surgery will reduce fear and motivate more patients to come for surgery as there is improvement in the patient's quality of life after cataract 
surgery. ${ }^{23}$

Although a good number of patients in this study had good visual outcome, it is still below the WHO recommendation of $90 \%$ with best correction, thus there is a need for good patient selection, biometry so that the correct power of IOL is inserted, reduction in the number and proper management of complications, proper surgical technique to reduce post-operative astigmatism. and ad equate correction of post op erative refractive errors. There is a need for regular monitoring of cataract visual outcome and surgeons should be encouraged to monitor their own results over time and identify causes of poor outcome. Addressing these cau ses will improve the future ou tcome of cataract surgeries and lead to better outcome. Better results will reduce fear and motivate more patients to come for cataract surgery.

There is also a need to improve aw areness of members of the community about the good visual ou tcome associated with cataract surgery and encourage them to seek surgery earlier before the onset of severe visual impairment or blindness, which will have significant economic and social impact on their lives. The availability of free cataract surgery at the University of Benin Teaching Hospital should be highly publicised to increase the uptake of cataract surgical services at the hospital, reduce the need for the use of harmful traditional eye medications and couching which have adverse effect on visual ou tcome after cataract surgery.

\section{CONCLUSION}

Cataract services uptake at the University of Benin Teaching Hospital has improved significantly since the inception of the free cataract surgery programme

The result of this study shows that although visual outcome was good in many $(59.7 \%)$ patients, it is still below the WHO recommendation of best corrected good visual outcome of $90 \%$. Good patient selection, preoperative biom etry, reduction of surgical complications and sequelae, appropriate spectacle correction, meticulous preoperative, intraoperative and postoperative care of the patients will ensure that the WHO recommendation is achieved.

\section{REFERENCES}

1. Parajasegaram R. Importance of monitoring cataract surgical outcomes. Comm Eye Health J2002; 15: 49-50.

2. The Nigerian National Blindness and Visual Impairment Survey, 2005-2007.

3. Umeh RE, Onwasigwe EN, Ozoh GA, Onwasigwe EN, Okoye OI, Umeh OC. Cataract intervention surgery: A community approach. Nig JOphthalmol 2000; 8: 17-20.

4. World Health Organisation. Management of cataract in primary Health care services. WHO. Geneva 1996.

5. Foster A. Vision 2020: The cataract challenge. Comm Eye Health J2000; 13 (34): 17-19.
6. Mangiona CM, Phillips RS, Law rence MA et al. Improved visual function and attenuation of declines in health related quality of life after cataract extraction. Arch Ophthalmol 1994; 112: 1419-25.

7. Monestan W, Wachmeister L. Impact of cataract surgery on visual acuity and subjective functional outcomes; a population based study in Sweden. Eye 1999; 13: 711-9.

8. WHO Informal consultation on analysis of blindness prevention outcomes. Geneva. World Health Organisation. WHO/ PBL/ 98/ 68.

9. Limburg H, Forster A, Vaidyanathan K, Murthy GV. Monitoring visual outcome of cataract surgery in India. Bull World Health Organ 1999; 77(6): 455-60.

11. Nwosu SNN, Onyekwe LO. Intraocular lens implantation surgery in Onitsha, Nigeria. Nigerian Journal of Ophthalmology 2002; 1: 5-9.

12. Adio AO, Awoyesuku E. Early experience with intraocular lens implantation surgery in University of Port-Harcourt Teaching Hospital, Nigeria. Port-Harcourt Medical Journal 2007; 1: 178-185.

13. Bekibele CO. Evaluation of the outcome of ECCE surgery with PC IOL at Ago-Iwoye, Ogun State, Nigeria. Nig J Ophthalmol 2001; 9: 32-36.

14. Singh SK, Dahal T, Sharma D. Early results of cataract surgeries in Mechi Eye Centre in Nepal. Comm Eye Health J2002; 15(42): 28-29.

15. Limburg H, Foster A, Gilbert C, Johnson GJ, Kyndt M, Myatt M. Routine monitoring of visual outcome of cataract surgery. Part 2: Results from eight study centres. Br JOphthalmol 2005; 89(1): 50-52.

16. Chirambo MC. Country wide monitoring of cataract surgical outcomes. Comm Eye Health J2002; 15: 58-59.

17. Adepoju FG, Owoeye JFA, Ademola-Popoola DS. Assessments of one year follow-up of patients with ECCE_PCIOL surgery at Ilorin Teaching Hospital, Kw ara State, Nigeria. Nig JOphthalmol 2004; 12: 65-67.

18. Cook C. How to improve the outcome of cataract surgery. Comm Eye Health J2000; 13: 37-39.

19. Walia T, Yorston D. Improving surgical outcomes. Comm Eye Health J2008; 21(66): 58-59.

20. Schein OD, Steinberg EP, Cassard SD et al. Predictors of outcome in patients who under went cataract surgery. Ophthalmology 1995; 102: 817-23.

21. Forooghian F, Agron El, Clemons ET, Ferris FL, Chew EY, Visual acuity after surgery in patients with age related macular degeneration; Age Related Eye Disease Study Report No 27, Ophthalmology 2009; 116(11): 2093- 100.

22. Waziri-Erameh JM, Omoti AE, Ped ro-Egbe CN. Non-Laser management of post extraction opacification of the posterior capsule. Nig JSurg Sciences 2007; 17: 101-4.

23. Odugbo OP, Babalola OE, Morgan R. Impact of cataract surgery on quality of life in Plateau State. Nig JOphthalmol 2009; 17: 5-10. 